\title{
Structural analysis reveals DNA binding properties of Rv2827c, a hypothetical protein from Mycobacterium tuberculosis
}

\author{
Robert Janowski · Santosh Panjikar • \\ Ali Nasser Eddine - Stefan H. E. Kaufmann • \\ Manfred S. Weiss
}

Received: 31 October 2008/Accepted: 14 January 2009/Published online: 31 January 2009

(C) Springer Science+Business Media B.V. 2009

\begin{abstract}
Tuberculosis (TB) is a major global health threat caused by Mycobacterium tuberculosis (Mtb). It is further fueled by the HIV pandemic and by increasing incidences of multidrug resistant Mtb-strains. Rv2827c, a hypothetical protein from Mtb, has been implicated in the survival of Mtb in the macrophages of the host. The threedimensional structure of Rv2827c has been determined by the three-wavelength anomalous diffraction technique using bromide-derivatized crystals and refined to a resolution of $1.93 \AA$. The asymmetric unit of the orthorhombic crystals contains two independent protein molecules related by a non-crystallographic translation. The tertiary structure of Rv2827c comprises two domains: an $\mathrm{N}$-terminal domain displaying a winged helix topology and a C-terminal domain, which appears to constitute a new and unique fold. Based on structural homology considerations and additional biochemical evidence, it could be established that Rv2827c is a DNA-binding protein. Once the understanding of the structure-function relationship of Rv2827c extends to the function of Rv2827c in vivo, new clues for the rational design of novel intervention strategies may be obtained.
\end{abstract}

R. Janowski · S. Panjikar · M. S. Weiss ( $₫)$

EMBL Hamburg Outstation, c/o DESY, Notkestrasse 85, 22603,

Hamburg, Germany

e-mail: msweiss@embl-hamburg.de

Present Address:

R. Janowski

IBMB (CSIC), Parc Científic de Barcelona, Baldiri Riexac 10-12, 08028 Barcelona, Spain

A. N. Eddine - S. H. E. Kaufmann

Max Planck Institute for Infection Biology, Charitéplatz 1,

10117, Berlin, Germany
Keywords X-ray crystallography · DNA binding · Mycobacterium tuberculosis - Hypothetical protein . Rv2827c · Winged helix domain

$\begin{array}{ll}\text { Abbreviations } \\ \text { HTH } & \text { Helix-turn-helix } \\ \text { Mtb } & \text { Mycobacterium tuberculosis } \\ \text { PDB } & \text { Protein Data Bank } \\ \text { TB } & \text { Tuberculosis } \\ \text { WH } & \text { Winged helix } \\ \text { wHTH } & \text { Winged helix-turn-helix }\end{array}$

\section{Introduction}

Globally, tuberculosis (TB) represents a major health threat with 9 million cases and close to 2 million deaths annually [80]. Although drugs to treat TB are available, the complex and long-lasting treatment scheme with three to four drugs over a period of 6-9 months leads to poor patient compliance. In several regions, notably in subSaharan Africa, the re-emergence of TB was further fueled by the pandemic with human immunodeficiency virus (HIV) responsible for acquired immunodeficiency syndrome (AIDS) [40]. As a corollary, incidences of multidrug-resistant (MDR) and even extensively drugresistant (XDR)-TB have increased profoundly. MDR-TB is resistant to treatment with first-line drugs, whereas XDR-TB is virtually untreatable with the currently available drugs. Drug development for TB has been largely neglected in the last decades and hence appropriate intervention methods to efficiently combat the re-emergent threat of TB are urgently required. The etiologic agent of TB, Mycobacterium tuberculosis (Mtb), is a 
bacterium capable of persisting in resting macrophages. After adequate activation by cytokines, notably interferon-gamma (IFN- $\gamma$ ), macrophages acquire increased antibacterial capacities. These activated macrophages can control Mtb growth though they fail to achieve sterile eradication [84]. Consequently, gene products essential for Mtb growth or persistence in resting or activated macrophages, respectively, represent potential targets for novel drugs.

Genome-wide expression profiling of microbial pathogens has become a useful tool to identify single genes and gene networks that are differentially expressed under different conditions. In numerous cases, these analyses have provided clues to gene functions and persistence. Among the close to 4,000 genes encoded by the H37Rv strain of Mtb [15, 21], a group of proteins has been identified in microarray experiments as being differentially expressed and therefore considered potentially important for persistence and pathogenicity of Mtb [66, 67]. Currently, only limited information on the threedimensional (3-D) architecture and the structural features of these proteins is available. It is well conceivable that the understanding of the 3-D structures of these proteins will provide a valuable basis for a better understanding of pathogenesis and persistence of Mtb and for structurebased design of novel intervention strategies against tuberculosis.

Based on its amino acid sequence, Rv2827c has been annotated as a hypothetical protein with unknown function [21]. The protein is composed of 295 amino acid residues with a molecular weight of $32.3 \mathrm{kDa}$ and an isoelectric point of 9.3. According to Sassetti et al. [70] and Lamichhane et al. [44], this protein is critical for Mtb replication. Mtb mutants lacking a functional copy of the $r v 2827 c$ gene fail to grow in vitro. The protein Rv2827c is approximately threefold upregulated upon infection of macrophages with $\mathrm{Mtb}$ in comparison to in vitro grown cultures of Mtb [66, 67]. IFN- $\gamma$ activation of macrophages leads to a further threefold increase as compared to the situation in resting macrophages. Based on these observations we proposed that Rv2827c plays a critical role in Mtb survival in macrophages and hence represents a potential target for future intervention strategies.

The crystallization and preliminary diffraction experiments for Rv2827c have recently been reported [38]. Here, we describe the X-ray structure of Rv2827c, solved by the MAD method [36] utilizing bromide-derivatized crystals [23]. The structure of Rv2827c and its potential function as a DNA binding protein will be described and discussed in detail. The elucidation of the structurefunction relationship for Rv2827c may provide a blueprint for the rational design of a drug candidate targeted at this molecule.

\section{Materials and methods}

Cloning, expression, purification and crystallization

The cloning, expression, purification, crystallization and preliminary X-ray diffraction experiments for the native crystals of Rv2827c have been described previously [38]. Briefly: recombinant, full-length $\mathrm{Rv} 2827 \mathrm{c}$, with three additional N-terminal residues (Gly-2, Ala-1 and Met0) introduced for cloning purposes, was crystallized from $2 \mathrm{M}$ sodium formate and $100 \mathrm{mM}$ sodium acetate $(\mathrm{pH}$ 4.7) supplemented with the 3-(1-pyridino)-1-propane sulfonate (aka non-detergent sulfo-betaine 201) or 6-aminocaproic acid at $277 \mathrm{~K}$. Single crystals grew out of the surface of spherulites within several weeks. The crystals are orthorhombic, space group $P 2{ }_{1} 2_{1} 2$ with unit-cell parameters $a=87.42 \AA, b=180.65 \AA$ and $c=35.11 \AA$ and diffract $\mathrm{X}$-rays to a resolution of better than $2.0 \AA$.

\section{Data collection and processing}

Due to the lack of a suitable search model for molecular replacement, three-wavelength MAD data were collected from a crystal soaked with $0.3 \mathrm{M} \mathrm{NaBr}$ (in crystallization buffer) for 2 days and additionally for $20 \mathrm{~min}$ in $0.5 \mathrm{M}$ $\mathrm{NaBr}$ (in crystallization buffer) immediately before the $\mathrm{X}$-ray experiment. A crystal with dimensions $200 \times 150 \times$ $150 \mu \mathrm{m}$ was mounted in a nylon fiber loop, cryo-protected for $10 \mathrm{~s}$ in reservoir solution containing $15 \%(\mathrm{v} / \mathrm{v})$ MPD and $0.5 \mathrm{M} \mathrm{NaBr}$ and flash-cooled to $100 \mathrm{~K}$ in a nitrogen gas stream. Diffraction data were then collected on the EMBL beamline BW7A (DESY, Hamburg, Germany) using a MARCCD detector. For all three wavelengths, $360^{\circ}$ of data were collected to $2.6 \AA$ resolution (Table 1). Data were indexed and integrated using DENZO [59] and scaled using SCALEPACK [59]. The redundancy-independent merging $\mathrm{R}$-factor $\mathrm{R}_{\mathrm{r} \text {.i.m. }}$ as well as the precision-indicating merging $\mathrm{R}$-factor $\mathrm{R}_{\text {p.i.m. }}$ [79] were calculated using the program RMERGE (available from http://www.emblhamburg.de/ $\sim$ msweiss/projects/msw_qual.html or from MSW upon request). Intensities were converted to structure-factor amplitudes using the program TRUNCATE [17, 26] and the optical resolution was calculated using the program SFCHECK [78].

Structure determination and refinement

The structure of Rv2827c was solved using the threewavelength MAD protocol of Auto-Rickshaw, the EMBLHamburg automated crystal structure determination platform [63]. The input diffraction data were uploaded to the Auto-Rickshaw server and then prepared and converted for 
Table 1 Data collection and processing statistics

\begin{tabular}{|c|c|c|c|c|}
\hline Number of crystals & 1 & 1 & & \\
\hline Beamline & $\mathrm{X} 13$ & BW7A & & \\
\hline Wavelength $[\AA]$ & 0.8031 & 0.9195 (peak) & 0.9203 (inflection) & 0.9095 (remote) \\
\hline Temperature $[\mathrm{K}]$ & 100 & 100 & & \\
\hline Crystal-to-detector distance $[\mathrm{mm}]$ & 180 & 210 & & \\
\hline Rotation range per image $\left[{ }^{\circ}\right]$ & 1.0 & 1.0 & & \\
\hline Total rotation range $\left[{ }^{\circ}\right]$ & 156 & 360 & & \\
\hline Space group & $P 2_{1} 2_{1} 2$ & $P 2_{1} 2_{1} 2$ & & \\
\hline \multirow[t]{3}{*}{ Unit cell parameters $[\AA]$} & $a=87.42$ & $a=87.48$ & $a=87.47$ & $a=88.58$ \\
\hline & $b=180.65$ & $b=180.79$ & $b=180.69$ & $b=182.95$ \\
\hline & $c=35.11$ & $c=35.43$ & $c=35.39$ & $c=35.82$ \\
\hline Mosaicity $\left[{ }^{\circ}\right]$ & 0.60 & 1.00 & 1.00 & 0.95 \\
\hline \multirow[t]{2}{*}{ Resolution limits $[\AA]]$} & $50.0-1.93$ & $99-2.60$ & & \\
\hline & $(2.00-1.93)$ & $(2.69-2.60)$ & & \\
\hline Total number of reflections & 268,981 & 257,694 & 257,209 & 258,683 \\
\hline Unique reflections & 43,027 & 18,227 & 18,143 & 18,166 \\
\hline Redundancy & 6.3 & 14.1 & 14.2 & 14.2 \\
\hline $\mathrm{I} / \sigma(\mathrm{I})$ & $23.3(3.7)$ & $30.3(5.8)$ & $32.8(6.9)$ & $27.9(5.7)$ \\
\hline Completeness [\%] & $99.9(99.8)$ & $99.9(99.2)$ & $99.9(99.7)$ & $99.9(100.0)$ \\
\hline $\mathrm{R}_{\text {merge }}[\%]^{\mathrm{a}}$ & $7.6(49.8)$ & $10.2(64.6)$ & $9.2(55.8)$ & $10.8(63.0)$ \\
\hline $\mathrm{R}_{\text {r.i.m. }}[\%]^{\mathrm{b}}$ & $8.3(54.8)$ & $10.7(76.7)$ & $9.4(59.5)$ & $11.3(66.8)$ \\
\hline $\mathrm{R}_{\text {p.i.m. }}[\%]^{\mathrm{c}}$ & $3.3(22.5)$ & $2.8(20.8)$ & $2.5(16.2)$ & $3.0(17.6)$ \\
\hline $\mathrm{R}_{\mathrm{anom}}[\%]^{\mathrm{d}}$ & - & $3.2(16.2)$ & $2.2(13.3)$ & $3.3(15.5)$ \\
\hline Overall B factor from Wilson plot $\left[\AA^{\mathrm{b}}\right]$ & 24.2 & 41.9 & 47.1 & 48.8 \\
\hline Optical resolution $[\AA ̊]$ & 1.55 & 1.88 & 1.89 & 1.91 \\
\hline
\end{tabular}

Values in parentheses correspond to the highest resolution shell

${ }^{\text {a }} R_{\text {merge }}=\Sigma_{h k l} \Sigma_{i} I_{i}(h k l)-\langle I(h k l)\rangle \mid / \Sigma_{h k l} \Sigma_{i} \mathrm{I}_{i}(h k l)$, where $I_{i}(h k l)$ is the intensity of the observation $i$ of the reflection $h k l$

${ }^{\mathrm{b}} R_{\mathrm{r} . \mathrm{i} . \mathrm{m}}=\Sigma_{h k l}(N /(N-1))^{1 / 2} \Sigma_{i} I_{i}(h k l)-\langle I(h k l)\rangle \mid / \Sigma_{h k l} \Sigma_{i} I_{i}(h k l)$, where $I_{i}(h k l)$ is the intensity of the observation $i$ of the reflection $h k l$ and $N$ is the redundancy

${ }^{\mathrm{c}} R_{\text {p.i.m }}=\Sigma_{h k l}(1 /(N-1))^{1 / 2} \Sigma_{i} I_{i}(h k l)-\langle I(h k l)\rangle \mid / \Sigma_{h k l} \Sigma_{i} I_{i}(h k l)$, where $I_{i}(h k l)$ is the intensity of the observation $i$ of the reflection $h k l$ and $N$ is the redundancy

${ }^{\mathrm{d}} R_{\mathrm{anom}}=\Sigma_{h k l}|I(h k l)-I(-\mathrm{h}-\mathrm{k}-1)| / \Sigma_{h k l}\langle I(h k l)\rangle$, where $I(h k l)$ and $I(-\mathrm{h}-\mathrm{k}-1)$ are the intensities of the reflections $h k l$ and $-\mathrm{h}-\mathrm{k}-\mathrm{l}$, respectively

use in Auto-Rickshaw using programs of the $\mathrm{CCP} 4$ suite [17]. $F_{A}$ values were calculated using the program SHELXC [74]. Based on an initial analysis of the data, the maximum resolution for substructure determination and initial phase calculation was set to $3.4 \AA$. Twenty-three bromide positions were located with the program SHELXD [71]. The correct hand for the substructure was determined using the programs ABS [34] and SHELXE [73]. The occupancy of all substructure atoms was refined using the program MLPHARE [17]. The initial phases were improved using density modification and phase extension to $2.60 \AA$ resolution using the program DM [22]. Approximately $50 \%$ of the model was built automatically using the program ARP/wARP $[52,65]$. The missing parts of the model were then added by assembling the intermediate models generated from ARP/wARP. As soon as the model was $80 \%$ complete, refinement was continued against the $1.93 \AA$ resolution native dataset. Refinement was performed in REFMAC5 [54] using the maximum likelihood target function including TLS parameters [82]. For TLS refinement, four TLS groups were used per protein chain (Gly-2-Ile80, Pro83-Asp94, Gly98-Thr253 and Val255-Gly293). In between refinement cycles, the structure was rebuilt manually in COOT [24]. The final model is characterized by $\mathrm{R}$ and $\mathrm{R}_{\text {free }}$ factors of $18.3 \%$ and $22.4 \%$, respectively (Table 2). Structural superpositions and searches were carried out using the program ALIGN [20] and the SSM server (http://www.ebi.ac.uk/msd-srv/ssm, [42]). Electrostatic potential analysis was performed using the GRASP [55] and PYMOL (www.pymol.org) programs. The stereochemistry of the final model was analyzed using PROCHECK [45]. The refined structure and corresponding structure-factor amplitudes have been deposited with the PDB under the accession code 1ZEL. 
Table 2 Refinement statistics

\begin{tabular}{ll}
\hline PDB code & 1ZEL \\
\hline Resolution limits $[\AA]$ & $30.0-1.93$ \\
Data cutoff $[\mathrm{F} / \sigma(\mathrm{F})]$ & 0.0 \\
Completeness [\%] & 99.9 \\
Total No. of reflections & 41,592 \\
No. of reflections in working set & 40,251 \\
No. of reflections in test set & 1,341 \\
R [\%] & 18.3 \\
R $_{\text {free }}[\%]^{\text {b }}$ & 22.4 \\
No. of amino acid residues & 588 \\
No. of protein atoms & 4,620 \\
No. of sodium ions & 2 \\
No. of acetate atoms & 8 \\
No. of MPD atoms & 8 \\
No. of formate atoms & 45 \\
No. of solvent atoms & 340 \\
R.m.s.d. bond lengths $[\AA]$ & 0.012 \\
R.m.s.d. bond angles $\left[{ }^{\circ}\right.$ ] & 1.38 \\
Ramachandran plot $[\%]:$ most favored/additionally & $92 / 8$ \\
allowed region & \\
\hline
\end{tabular}

${ }^{\mathrm{a}} R=\Sigma_{h k l}|| F_{\mathrm{o}}|-| F_{\mathrm{c}}|| / \Sigma_{h k l}\left|F_{\mathrm{o}}\right|$ for all reflections, where $F_{\mathrm{o}}$ and $F_{\mathrm{c}}$ are observed and calculated structure factors, respectively

${ }^{\text {b }} R_{\text {free }}$ was calculated against $3.2 \%(1,341)$ of all reflections, randomly excluded from the refinement

\section{Domain division}

For the definition of domains in the 3-D structure of Rv2827c, various approaches were used. First, the structure was analyzed using the program 123D+ (http://123d. ncifcrf.gov/123D+.html, [1]), which combines sequence profiles, secondary structure prediction, and contact capacity potentials to thread a protein sequence through the set of structures. Secondly, the vector alignment search tool VAST Search [31, 48] was employed using services of the National Center for Biotechnology Information (NCBI, http://www.ncbi.nlm.nih.gov/Structure/VAST/vast.shtml).

VAST defines domains based on structure similarity searches. Thirdly, automatic domain definition was attempted by analyzing accessible surface areas (ASA) on a residue by residue basis. A high value of ASA $\left(>100 \AA^{2}\right)$ for a few adjacent residues indicates that a particular sequence fragment is well exposed and may thus constitute a linker or a hinge between domains. This calculation was carried out using the PISA server [43]. A further attempt on domain definition was made using a normal mode calculation [76] using the elNemo server (http://www.igs.cnrsmrs.fr/elnemo/index.html). Finally, a TLS group analysis was performed using the TLS Motion Determination server (TLSMD, http://skuld.bmsc.washington.edu/ tlsmd/,
$[60,61])$. For this analysis, the protein was divided into two to six TLS groups.

Initial DNA binding test

Without any information about the potential DNA sequence being recognized by Rv2827c, initial DNA binding tests were performed with four dsDNA fragments (Table 3), taken from the structures of various DNA binding proteins containing a wHTH motif: 5'-GGTTCTA GAACC-3' (PDB code 3HTS, [46]), 5'-CTATGTAGTCTG TTG-3' (PDB code 1RH6, [69]), 5'-AAAAAGGGGAAGT GGG-3' (PDB code 1PUE, [41]), and 5'-GAGAAGTGAA AGTACTTTCACTTCTC-3' (PDB code 1IF1, [25]). The oligonucleotides were obtained from MWG Biotech and dissolved in a buffer composed of $10 \mathrm{mM}$ Tris $\mathrm{pH} 8.5$, $50 \mathrm{mM} \mathrm{NaCl}, 1 \mathrm{mM}$ EDTA. In order to obtain a double stranded form, the palindromic fragments $5^{\prime}$-GGTTCTA GAACC-3' and 5'-GAGAAGTGAAAGTACTTTCACTT CTC $-3^{\prime}$ were annealed at $95^{\circ} \mathrm{C}$ for $10 \mathrm{~min}$ and left for slow cooling. The other two fragments $5^{\prime}$-CTATGTAGTCTG TTG- $3^{\prime}$ and $5^{\prime}$-AAAAAGGGGAAGTGGG-3' were mixed with their complementary fragments $5^{\prime}$-CAACAGACTAC ATAG- $3^{\prime}$ and $5^{\prime}$-CCCACTTCCCCTTTTT- $3^{\prime}$, respectively and prior to annealing them as described above. Equimolar amounts of Rv2827c (in $50 \mathrm{mM}$ Tris $\mathrm{pH} 7.3,150 \mathrm{mM} \mathrm{KCl}$, $350 \mathrm{mM}$ imidazole, $2 \mathrm{mM}$ DTT) and the corresponding dsDNA fragments were mixed and dialyzed overnight against a buffer composed of $50 \mathrm{mM}$ Tris ( $\mathrm{pH} 7.3$ ), $150 \mathrm{mM} \mathrm{KCl}$ and $2 \mathrm{mM}$ DTT to slowly remove the imidazole present in the protein sample [38].

PCR-assisted binding site selection method

The polymerase chain reaction (PCR) assisted binding site selection method used here was described earlier by Nørby et al. [56]. The following ssDNA fragment was designed and obtained from MWG Biotech: 5'-CAATCCATGGCG ACTCTGCATCCGC $(\mathrm{N})_{30}$ GTGTCACCGGCATGACTCG AGACCA-3'. It contains 30 nucleotides with a random sequence flanked on both sides by a 25-base long conserved fragment with recognition sites for $\mathrm{NcoI}$ and XhoI at the $5^{\prime}$ and $3^{\prime}$ ends, respectively. The recognition sites (underlined) were necessary for subcloning purposes.

Table 3 DNA sequences tested for DNA binding

\begin{tabular}{lll}
\hline DNA sequence $5^{\prime}-3^{\prime}$ & $\mathrm{G}+\mathrm{C}[\%]$ & Stabilizing \\
\hline GGTTCTAGAACC & 50 & $\mathrm{Y}$ \\
CTATGTAGTCTGTTG & 40 & $\mathrm{Y}$ \\
AAAAAGGGGAAGTGGG & 50 & $\mathrm{Y}$ \\
GAGAAGTGAAAGTACTTTCACTTCTC & 38 & $\mathrm{~N}$ \\
\hline
\end{tabular}


The primers $5^{\prime}$-CAATCCATGGCGACTCTGCATCCGC$3^{\prime}$ (forward) containing a recognition site for $N c o I$, and $5^{\prime}$-TGGTCTCGAGTCATGCCGGTGACAC-3' (reverse) with an XhoI recognition site were designed for PCR amplification. The ssDNA fragment was converted to dsDNA by means of DNA polymerase I Klenow fragment and the reverse primer. For the protein-DNA binding test, $2 \mu \mathrm{l}$ of $10 \mathrm{mg} / \mathrm{ml} \mathrm{Rv} 2827 \mathrm{c}$ were spotted onto $1 \mathrm{~cm}^{2}$ of nitrocellulose membrane and air dried. The filter was blocked by washing it for $30 \mathrm{~min}$ at $4^{\circ} \mathrm{C}$ in a buffer composed of $50 \mathrm{mM}$ Tris $\mathrm{pH} \mathrm{7.3,} 40 \mathrm{mM} \mathrm{KCl,} 3 \mathrm{mM} \mathrm{MgCl}_{2}$, $2 \mathrm{mM}$ DTT and $0.5 \%(\mathrm{w} / \mathrm{v})$ carnation milk. The membrane was exposed overnight at $4^{\circ} \mathrm{C}$ to $200 \mu \mathrm{l}$ of the binding

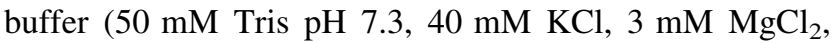
$2 \mathrm{mM}$ DTT) supplemented with $10 \mathrm{pmol}$ of the random dsDNA described above. Afterwards, the membrane was extensively washed in binding buffer first with $0.5 \%(\mathrm{w} / \mathrm{v})$ carnation milk and then without. As a control, the membrane without Rv2827c was exposed to the mixture of random dsDNA. To dissociate DNA bound to the protein (and to the membrane in the control experiment), the membrane was washed in $0.5 \mathrm{M} \mathrm{KCl}$ and to check for the presence of DNA in the eluted samples and to amplify it, PCR was performed using the primers described above. Four different samples were investigated: (1) the eluent from the control membrane washed in washing (low salt) buffer and (2) in $0.5 \mathrm{M} \mathrm{KCl}$, (3) the eluent from the membrane with immobilized Rv2827c washed in low salt buffer (as additional control) and (4) in $0.5 \mathrm{M} \mathrm{KCl}$. The latter sample (4) was then used for the next round of the experiment. The whole procedure was repeated seven times. After each cycle of binding, PCR was performed to analyze the quality and quantity of binding. After the final cycle, the amplified DNA fragments were digested with $\mathrm{NcoI}$ and XhoI and subcloned into the corresponding sites of pETM-11 vector containing a kanamycine resistance. TOP10 cells (Invitrogen) were transformed with the recombinant plasmid. The presence of the inserted DNA fragment was verified by PCR. Seventeen randomly selected clones were sent for oligonucleotide sequencing (Table 4).

Modeling the complex of Rv2827c with dsDNA

In order to construct a model of the Rv2827c/DNA-complex, the N-terminal domain of Rv2827c was superimposed onto the winged helix domain of the interferon regulatory factor 3 (IRF-3, PDB code 1T2 K, [64]) complexed with a 31-mer DNA fragment. Then, the C-terminal domain (residues Pro83-Ala295) was manually rotated and translated toward the DNA using the molecular graphics program COOT [24]. By repeating this operation with C-terminal fragment Asp94-Ala295 the fit of Rv2827c onto
Table 4 DNA sequences identified by PCR-assisted binding site selection method

\begin{tabular}{|c|c|}
\hline DNA sequence $\left[5^{\prime}-3^{\prime}\right]$ & $\mathrm{G}+\mathrm{C}[\%]$ \\
\hline CCCCTGCAACGGCGCACACCAACACACATC & 63 \\
\hline TCTAGGACATATTGTTTAAACGCCAGCACC & 43 \\
\hline TGCGTTTATGTGTTTCTTGGGGTTGGCAGG & 50 \\
\hline GCACGCCACACTCACCATGCAGGACAACCT & 60 \\
\hline ATATCGCAGATGACTGATTACCACCCTTCA & 43 \\
\hline TTTGAAAAAAGGGAGATGCATAATCATTAT & 27 \\
\hline AGTTCACACATTGCAGTTATGGCTGGTGGG & 50 \\
\hline ATCCCAGGCATGACGGTTGGCTCTGACCCA & 60 \\
\hline GCCGATTGCTTTTTCTTATTAGGGGGGCTA & 47 \\
\hline AGAAACAGAATGAGAAGGTCGCACAGCACC & 50 \\
\hline CCATTCGCAGATATGAGAAAAAGAGCGAGT & 43 \\
\hline CGGCATAACACATAGAGACCGTACACCCTT & 50 \\
\hline CTTACCCCCGACCATATTGTTCTACCCCCC & 57 \\
\hline TGGGCTAGCCTGGTAGCGCTCTGTTGATTT & 53 \\
\hline TAGCTGTTTGTGTTCGCTCGCGTGTTTGTA & 47 \\
\hline AAAACCAGGGGAAGTGAAAAGAAACACCCT & 43 \\
\hline GAAACAACCACGTCTAAGTCAGCCATCCCC & 53 \\
\hline \multicolumn{2}{|l|}{ Complementary DNA $\left[5^{\prime}-3^{\prime}\right]$} \\
\hline GATGTGTGTTGGTGTGCGCCGTTGCAGGGG & 63 \\
\hline GGTGCTGGCGTTTAAACAATATGTCCTAGA & 43 \\
\hline CCTGCCAACCCCAAGAAACACATAAACGCA & 50 \\
\hline AGGTTGTCCTGCATGGTGAGTGTGGCGTGC & 60 \\
\hline TGAAGGGTGGTAATCAGTCATCTGCGATAT & 43 \\
\hline ATAATGATTATGCATCTCCСТTTTTTCAAA & 27 \\
\hline CCCACCAGCCATAACTGCAATGTGTGAACT & 50 \\
\hline TGGGTCAGAGCCAACCGTCATGCCTGGGAT & 60 \\
\hline TAGCCCCCCTAATAAGAAAAAGCAATCGGC & 47 \\
\hline GGTGCTGTGCGACCTTCTCATTCTGTTTCT & 50 \\
\hline ACTCGCTCTTTTTCTCATATCTGCGAATGG & 43 \\
\hline AAGGGTGTACGGTCTCTATGTGTTATGCCG & 50 \\
\hline GGGGGGTAGAACAATATGGTCGGGGGTAAG & 57 \\
\hline AAATCAACAGAGCGCTACCAGGCTAGCCCA & 53 \\
\hline TACAAACACGCGAGCGAACACAAACAGCTA & 47 \\
\hline AGGGTGTTTCTTTTCACTTCCCCTGGTTTT & 43 \\
\hline GGGGATGGCTGACTTAGACGTGGTTGTTTC & 53 \\
\hline
\end{tabular}

the DNA can be markedly improved. Further minor adjustments in the loop between Leu125 and Val139 followed by geometry idealisation resulted in the final model.

\section{Results and discussion}

Analysis of the primary structure of Rv2827c

A sequence similarity search using the programs BLAST and PSI-BLAST [2] provided only limited information 
about homologues of Rv2827c in other organisms. The sole exception is the hypothetical protein Mb2851c from M. bovis [29] with $100 \%$ sequence identity to Rv2827c. Further hits, albeit at a much lower confidence level, include phosphoribosylaminoimidazole carboxylase from Azospirillum brasilense [16] (EMBL/GenBank/DDBJ databases), with $26 \%$ identity and $53 \%$ similarity for a 255 amino acid overlap, a hypothetical protein from Pseudomonas sp. WBC-3 [47] with $28 \%$ identity and $50 \%$ similarity in a 264 aa overlap and the hypothetical protein SCO15 from Streptomyces coelicolor [6] with $29 \%$ identity and $46 \%$ similarity in a 256 aa overlap. Searches with shorter sequence fragments revealed that the first 133 amino acids of Rv2827c exhibit 25\% identity and 38\% similarity to seryl-tRNA synthetase from Methanopyrus kandleri [75]. The short fragment Asp133-Leu184 displays some evidence for a leucine-zipper motif $\left(\mathrm{LX}_{6}\right)_{4}$ and shares 52\% identity and $69 \%$ similarity with the putative integral membrane protein from S. avermitilis [57]. The sequence region Ala172-Glu254 appears to be homologous to a putative serine/threonine protein kinase from S. coelicolor [6] with $34 \%$ identity and $45 \%$ similarity. Rv2827c has not been associated with any superfamily in the COG [77] or Pfam databases [4]. The only information about its potential function comes from the function prediction program ProKnow [62], which predicts that Rv2827c may have ATP binding activity or may participate in pantothenate biosynthesis as well as protein amino acid phosphorylation. However, the evidence ranks [62], are low and comparable for all three functions. Therefore, the predicted information is not really reliable. To date, no tertiary structure has been reported to the Protein Data Bank (PDB) [7] for any protein similar to Rv2827c. The highest score from sequence-based search against the PDB identifies 6-hydroxymethyl-7,8-dihydropterin pyrophosphokinase from Escherichia coli (PDB code: 1RU1, [8]) with $29 \%$ identity for the 120-residue long fragment between Leu175 and the C-terminus of Rv2827c as a potential homologue.

Quality of the structure

The final refined model of Rv2827c consists of amino acids Ala-1 to Ala295 in chain A and Gly-2 to Ala295 in chain B with the exception of the solvent-exposed loop Arg267Arg269 in both chains. It also includes 340 water molecules, two sodium ions, one MPD molecule, 15 formate ions and two acetate ions. Based on the refinement statistics and stereochemical parameters (Table 2) the quality of the model is high. About $92 \%$ of all residues are in the core region of the Ramachandran plot and no residues appeared in the generously allowed or unfavorable area. The rootmean-square deviation (r.m.s.d.) value between the two independent molecules in the asymmetric unit is $0.32 \AA$ for 276 pairs of superimposed $\mathrm{C} \alpha$ atoms, which is not significantly higher than the overall coordinate error of the structure.

The overall fold of Rv2827c and its topology

The protein structure consists of $15 \alpha$-helices and 12 $\beta$-strands and belongs to the class $3, \alpha / \beta$ family according to the CATH protein structure classification [58] (Fig. 1a, b). The N-terminal part starts with a short $\beta$-strand $(\beta 1)$ composed of Ala-1-Ser3. Even though the residues Ala-1 and Met0 are a cloning artifact (together with Gly-2 which is visible only in chain B), it can be expected that in the native protein, which starts with Vall, the structure is the same, albeit shorter by three amino acids. Three main

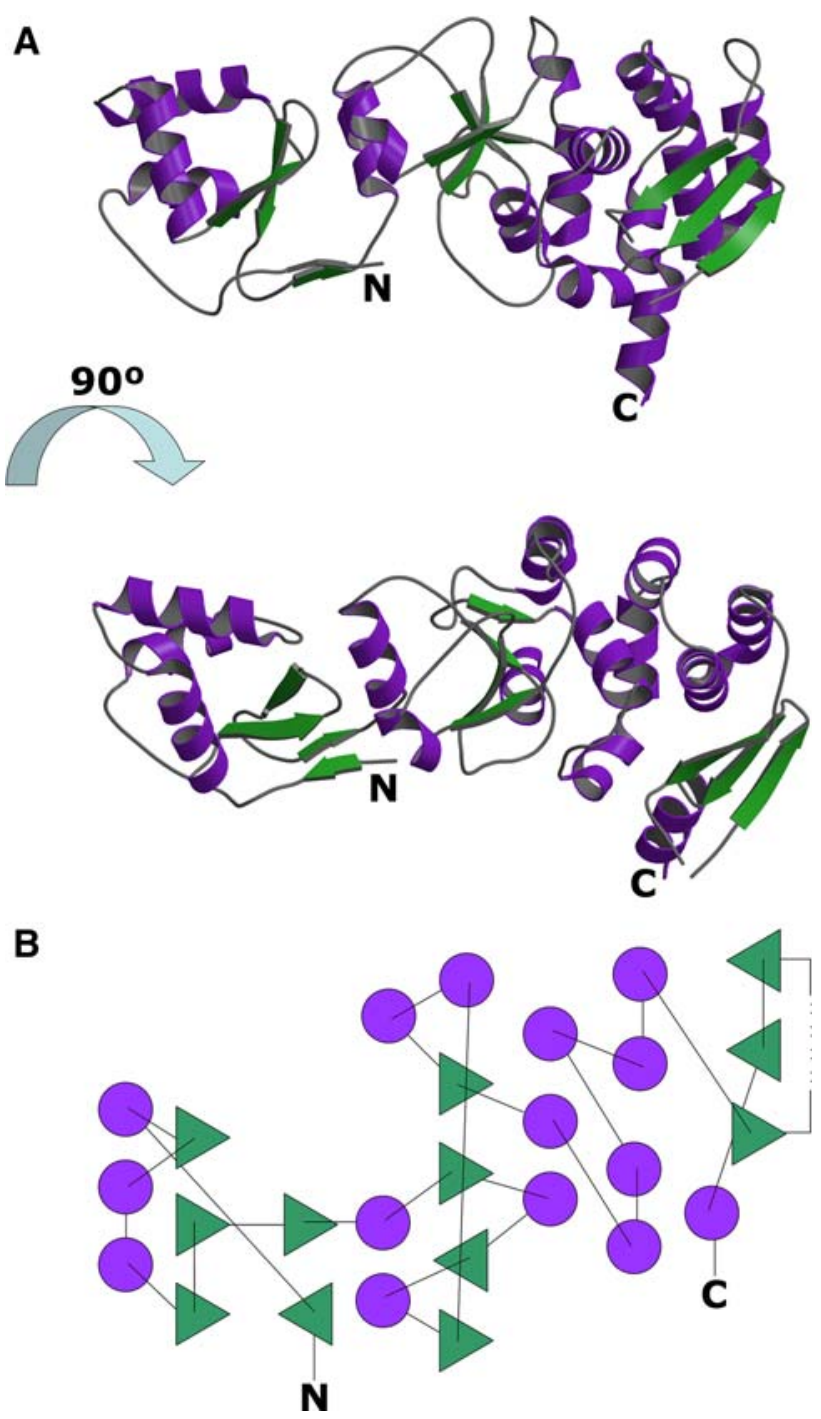

Fig. 1 The three-dimensional structure of Rv2827c from M. tuberculosis: a Ribbon representation of Rv2827c. b Topology diagram. Color codes for $\mathrm{A}$ and $\mathrm{B}$ : $\beta$-sheet, green; $\alpha$-helices, magenta 
chain-main chain hydrogen bonds connect the fragment Val1-Ser3 to strand $\beta 5$ (Ala78-Ser81) in an antiparallel fashion. The residues Ala-1 and Met0 strengthen this antiparallel $\beta$-sheet with an additional main chain-main chain hydrogen bond which connects Ala-1 to Asp82 located at the $\mathrm{C}$-terminus of the strand $\beta 5$. After leaving the first $\beta$-strand, the polypeptide chain continues as a loop and then enters the three-helix bundle, which is built up of helices $\alpha 1$ (Ala15-Arg26), $\alpha 2$ (Lys32-Ala42) and $\alpha 3$ (Pro48-Ile58). Helices $\alpha 2$ and $\alpha 3$ form a helix-turn-helix motif followed by a $\beta$-hairpin consisting of the strands $\beta 3$ (Leu61-Leu64) and $\beta 4$ (Thr69-Ile73), which, together with the short strand $\beta 2$ (Val29-Thr31) form a three-stranded antiparallel $\beta$-sheet. Following another loop is the short strand $\beta 5$ (Ala78-Ser81), which interacts with $\beta 1$ in an antiparallel fashion. The entire fragment between $\alpha 1$ and $\beta 4$ exhibits the canonical winged helix (WH) fold making Rv2827c a member of the WH or the winged helix-turnhelix (wHTH) family. The canonical WH motif consists of two wings (W1 and W2) which are extended loop structures, three $\alpha$ helices ( $\mathrm{H} 1, \mathrm{H} 2$, and $\mathrm{H} 3$ ) and three $\beta$-strands (S1, S2, and S3), arranged in the order H1-S1-H2-H3-S2W1-S3-W2 [19, 68]. In Rv2827c, the order is as follows: $\alpha 1-\beta 2-\alpha 2-\alpha 3-\beta 3-\mathrm{W} 1-\beta 4-\mathrm{W} 2$ where $\mathrm{W} 1$ and W2 correspond to the fragments Pro65-Gly68 and Pro74-Glu77, respectively.

Residues Tyr84-Asp94 form the helical fragment $\alpha 4$ occurring between the $\mathrm{N}$ - and C-terminal parts of Rv2827c. Helix $\alpha 4$ leads to a four-stranded mixed $\beta$-sheet exhibiting the topology $\beta 9-\beta 6-\beta 7-\beta 8$. Further $\alpha$-helical fragments occur in the loops connecting the $\beta$-strands: Helix $\alpha 5$ (Gly103-Leu110) between strands $\beta 6$ (Met100-Ala102) and $\beta 7$ (Ile121-Leu125), helix $\alpha 6$ (Asp133-Ser137) between $\beta 7$ and $\beta 8$ (Val139-Val142), and the two helices $\alpha 7$ (Asp150-Leu154) and $\alpha 8$ (Arg157-Arg164) before strand $\beta 9$ (Pro176-Leu178). After leaving the $\beta$-sheet, the protein chain enters the $\alpha$-helical region composed of helices $\alpha 9$ (Gly179-Arg190), $\alpha 10$ (Pro196-Val201) and $\alpha 11$ (His203-Asp210). These three helices are arranged in a circular structure separating the $\beta$-sheet and the three-helix bundle consisting of the almost parallel helices $\alpha 12$ (Ser212-Ser221), $\alpha 13$ (Pro224-Gly238), and $\alpha 14$ (Glu240Ala249). The last part of Rv2827c structure consists of the three-stranded mixed $\beta$-sheet with the topology $\beta 10-\beta 12$ $\beta 11$, which comprises the sequence segments Val258Thr262, Gln279-Glu283 and Ser272-Ala275, respectively. The polypeptide chain is terminated with the helical segment $\alpha 15$ (Leu284-Ala295) that points into the solvent.

Division of the structure into domains

The division of the Rv2827c structure into domains turned out to be somewhat ambiguous (Fig. 2). The program
123D+ [1] divides Rv2827c into three domains: Gly-2Ala97, Gly98-Leu183 and Leu184-Ala295. While the predicted border between the first two domains appears to be reasonable, the one between domains 2 and 3 occurs exactly in the middle of helix $\alpha 9$ (Gly179-Arg190) and it is buried in the protein core. The vector alignment search tool VAST Search [31, 48] predicts four domains: Gly-2-Gly98, Phe99-Ala152, Leu175-Val255 and Met256-Ala295, where the first predicted domain is identical to the one predicted by the program $123 \mathrm{D}+$. This can be explained that for this part of the structure many related structures are available. The fragment Phe99-Ala152 was assigned as the next domain although it does not show any similarity to any known 3-D structures. The sequence Leu153-Gly174 was left out of the domain prediction by VAST and the next segment Leu175-Val255 was recognized as a separate domain. The last sequence stretch (Met256-Ala295) was again recognized as a separate domain. This fragment corresponds to the three-stranded $\beta$-sheet terminated by an $\alpha$-helix. The assignment of this stretch to a domain is probably sensible, since it interacts with the rest of the molecule mostly by means of hydrophobic contacts. The difficulties of VAST in assigning domains in the C-terminal part of Rv2827c are a consequence of the lack of structural homologues for this region. This in turn corroborates the notion that the C-terminal part of Rv2827c constitutes a novel fold. By examining the solvent-accessible surface area (ASA) on a residue-by-residue basis using the PISA server [43] two potential linker regions were defined: Arg93-Asn96 and Lys250-Val255, thus dividing Rv2827c into three domains. The calculation of the normal modes using the ElNemo server [76] for Rv2827c divides the structure into two domains: Gly-2 to Ser81 and Asp82 to Ala295. The definition of the first domain contradicts to some extent the definitions of the programs $123 \mathrm{D}+$ and VAST in that it assigns the helical fragment $\alpha 4$ (Tyr84-Asp94) to the C-terminal domain of Rv2827c rather than the N-terminal. The segment Tyr84Asp94 exhibits strong interactions with both $\mathrm{N}$ - and Cterminal parts of the protein. The residues Tyr84, Leu87 and Trp90 are surrounded by the hydrophobic side chains of Ala97, Phe99, Leu101, Ile121, Ile123, Leu125, Leu131, Leu135 and Val139 from the C-terminal part of Rv2827c. Furthermore, the segment participates in the hydrogen bonds Tyr84-OH...His109-NE2, Arg88-NH1...Thr173-O and Arg88-NH2...Thr173-OG1. On the other side of $\alpha 4$, Leu85 and Ala92 interact with the hydrophobic side chains of Val1, Ile80, Val28 and Val29 of the N-terminal part, Ser89-OG forms a hydrogen bond with Val66-N and the side chains of Arg93 and Glu33 are connected by a salt bridge. Based on these considerations the segment Tyr84Asp94 should probably be considered part of the C-terminal domain rather than the N-terminal. Similarly, the 
Fig. 2 The definition of structural domains of Rv2827c using various computational approaches

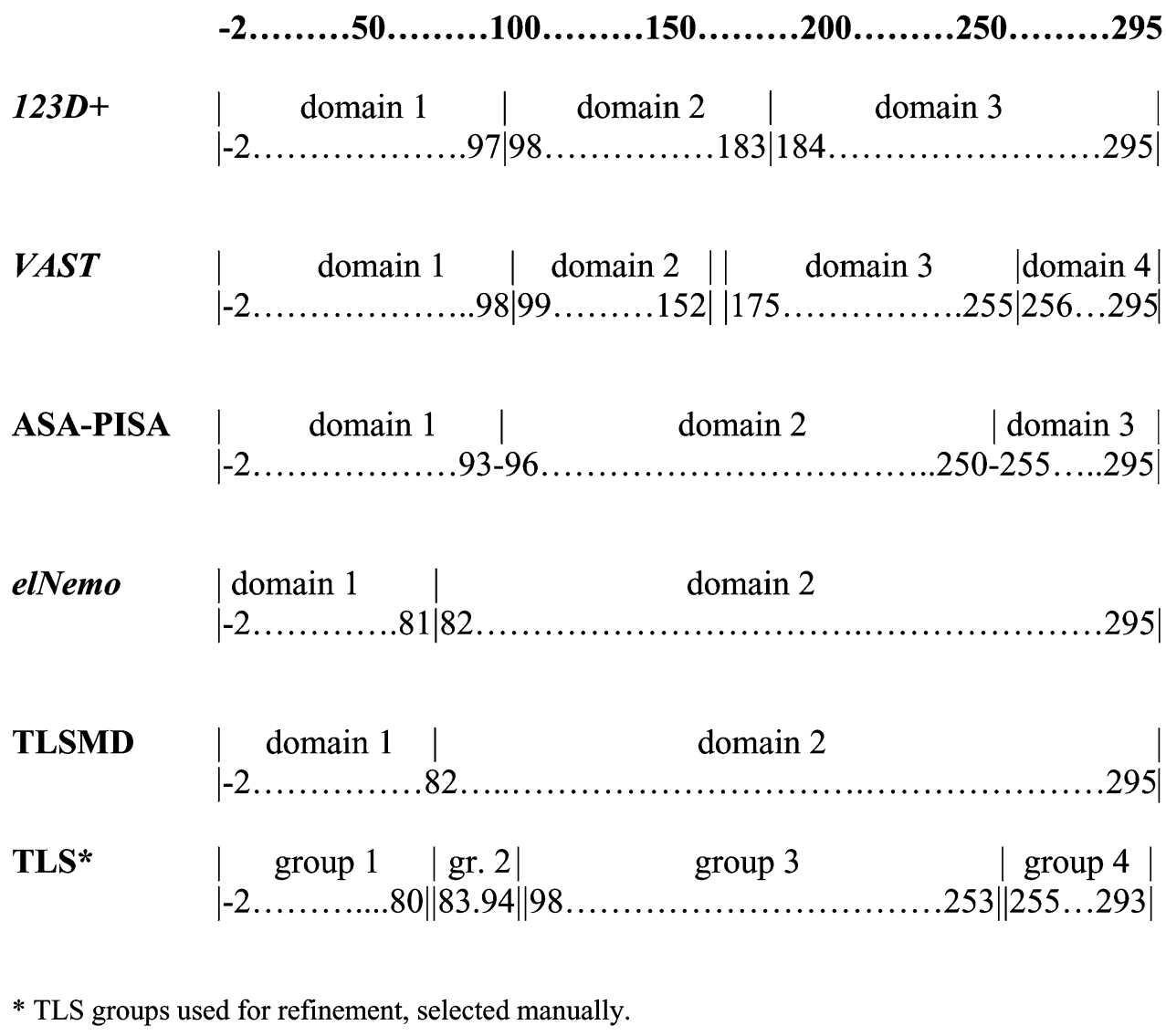

analysis of the refined B-factors using the TLS Motion Determination (TLSMD, server $[60,61]$ ) defined the border between the $\mathrm{N}$-terminal domain and the rest of protein molecule between Ile80-Ser81 and Ser81-Asp82. The division of the C-terminal part into further TLS groups was unclear and did not yield any indication about potential further domain division, similar to the other programs mentioned above. Rv2827c is therefore most sensibly divided into two structural domains.

The N-terminal domain of Rv2827c exhibits DNA binding features

Table 5 shows the top scored structures related to the Nterminal domain fragment Thr13-Ile73 of Rv2827c identified by the secondary structure matching (SSM) server. Most of these proteins interact with DNA. The structure superposition shown in Fig. 3 clearly indicates the structural similarity between the N-terminal domain of Rv2827c and other proteins belonging to the WH or wHTH family. To date, many X-ray structures of WH proteins have been determined. Whereas the first structures were those of eukaryotic proteins, such as the hepatocyte nuclear factor 3 (HNF-3) [19] and histone H5 [68], it was soon recognized that the WH motif is common to eukaryotes and prokaryotes [9]. The most prominent feature of the WH motif is the presence of the two helices $\mathrm{H} 2$ (the stabilization helix) and $\mathrm{H} 3$ (the recognition helix) and the turn between them, the length of which is variable [27]. In the majority of WH protein structures $\mathrm{H} 3$ is responsible for the interaction with DNA. One exception to this rule is the human regulatory factor $\mathrm{X} 1$ where the $\mathrm{W} 1$ face is responsible for DNA binding [28]. In WH proteins, the H3 helix typically lies in the major groove and makes most of the sequence-specific contacts with nucleic acids via a number of hydrogen bonds and hydrophobic interactions [10]. A superposition of the N-terminal domain of Rv2827c with structures of protein-DNA complexes such as heat shock transcription factor (PDB code 3HTS, [46]), serum response factor (PDB code 1K6O, [51]), transcription factor Pu.1 (PDB code 1PUE, [41]), or interferon regulatory factor (PDB code 1IF1, [25]) indicates that the sequence fragment 48-ProAspSerAlaIleArgGluLeuArgArgIle-58 of Rv2827c $(\alpha 3)$ might be responsible for the interaction with DNA. The presence of three Arg residues in the fragment further supports this hypothesis. An analysis of the electrostatic surface potential (Fig. 4) reveals that one side of the protein is negatively charged and includes a metal binding site whereas the other side shows a continuous path of positive potential extending along the whole molecule including the 
Table 5 Structures related to the N-terminal domain of Mtb Rv2827c identified by secondary structure matching [42]

\begin{tabular}{|c|c|c|c|c|c|c|c|c|c|}
\hline Rank & $\begin{array}{l}\text { Q- } \\
\text { score }\end{array}$ & $\begin{array}{l}\text { Z- } \\
\text { score }\end{array}$ & 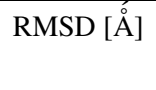 & $\mathrm{N}_{\text {aligned }}$ & $\begin{array}{l}\text { Fragment } \\
\text { aligned }\end{array}$ & Identity [\%] & PDB:chain & Function & Reference \\
\hline n.a. & 1.00 & 8.8 & 0.00 & 61 & Thr13-Ile73 & 100 & 1ZEL:A & Probably DNA binding & This work \\
\hline 1 & 0.55 & 3.5 & 2.03 & 57 & Glu3-Lys66 & 12 & 1WQ2:B & Reductase & [18] \\
\hline 2 & 0.54 & 4.2 & 1.93 & 52 & Asp112-Gly169 & 12 & 2HEO:D & DNA binding & [49] \\
\hline 3 & 0.53 & 3.9 & 1.97 & 54 & Asp138-Ala198 & 19 & 1QBJ:B & RNA binding & {$[72]$} \\
\hline 4 & 0.51 & 4.8 & 2.38 & 59 & Val207-Thr267 & 12 & 1Z1D:A & Replication & {$[3]$} \\
\hline 5 & 0.46 & 3.4 & 2.49 & 54 & Ser14-Thr73 & 21 & 1OYI:A & RNA binding & [39] \\
\hline 6 & 0.44 & 3.9 & 2.24 & 54 & Glu12-Asn72 & 17 & 1SFU:A & DNA binding & {$[32]$} \\
\hline 7 & 0.44 & 3.5 & 2.38 & 55 & Lys483-Lys556 & 11 & $1 \mathrm{~W} 1 \mathrm{~W}: \mathrm{G}$ & DNA binding & {$[33]$} \\
\hline 8 & 0.43 & 4.3 & 2.23 & 54 & Ser4-Leu70 & 11 & 2JT1:A & Transcription & Aramini et al. unpubl. data \\
\hline 9 & 0.43 & 2.9 & 2.65 & 59 & Thr27-Ala96 & 10 & 1HST:A & Chromosomal protein & {$[68]$} \\
\hline 10 & 0.42 & 3.1 & 2.29 & 58 & Asp9-Asn71 & 6 & 1P6R:A & Penicillinase repressor & {$[50]$} \\
\hline
\end{tabular}

The list is sorted by the $Q$-score. Other quality indicators of a structural alignment are also given as the $Z$-score, the r.m.s.d. value between the aligned stretches, the number of aligned residues and the percent amino acid sequence identity

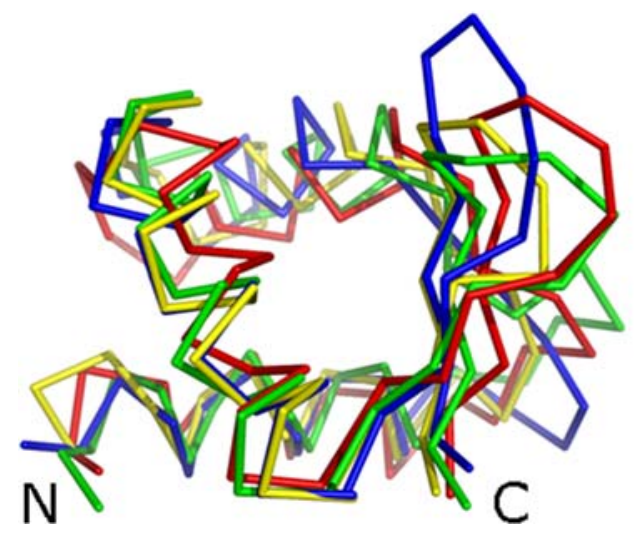

Fig. 3 Stereo view of the superposition of the winged helix domain of Rv2827c (fragment Thr13-Ile73, in red) with the globular domain of histone H5 (PDB code 1HST, [68], fragment Thr27-Ala96, in green), the viral Zalpha domain (PDB code 1SFU, [32], fragment

potential nucleic acid binding motif in the N-terminal domain containing the helix $\alpha 3$. The second and third helices of the WH unit form a HTH variant motif containing a longer turn than the corresponding turn in canonical HTH proteins [10]. The HTH motif has been found in many DNA binding proteins that regulate gene expression and also in proteins involved in DNA repair and replication, as well as in RNA metabolism. It consists of two helices connected by the turn, in which Gly is usually found in its first [10] or second position [37]. The length of the turn connecting two helices of the typical HTH motif is 3 or 4 residues. In Rv2827c the HTH motif is built up of 27 residues, characterized by helices $\alpha 2$ (Lys32-Ala42) and $\alpha 3$ (Pro48-Ile58) linked by a five-residue turn which contains two Gly residues (Gly43 and Gly45). Although the turn contains two

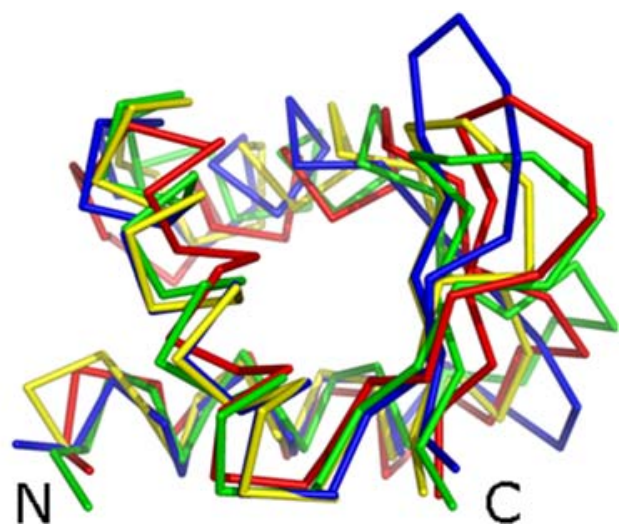

Glu12-Asn72, in blue), and Z-DNA binding protein 1 (PDB code 2HEO, [49], fragment Asp112-Gly169, in yellow). The figure was prepared with the program PYMOL (www.pymol.org)

extra residues, its conformation resembles more closely the typical HTH motif than that found in WH proteins. In contrast, the angle between the two helices is approximately $100^{\circ}$ although for a typical HTH motif it is usually about $120^{\circ}$ [11]. For $\mathrm{WH}$ proteins, the angle between the two helices ranges from $100^{\circ}$ in biotin operator repressor protein BirA [81] to $150^{\circ}$ in transcription factor DP2 [85].

The C-terminal domain constitutes a novel fold

A structural search using the entire C-terminal domain did not yield any similarity hits to other known structures. Only when smaller segments were used, similar motifs were found in other protein structures. For the fragment Ile80-Pro145, the highest scoring structure identified by SSM is the 


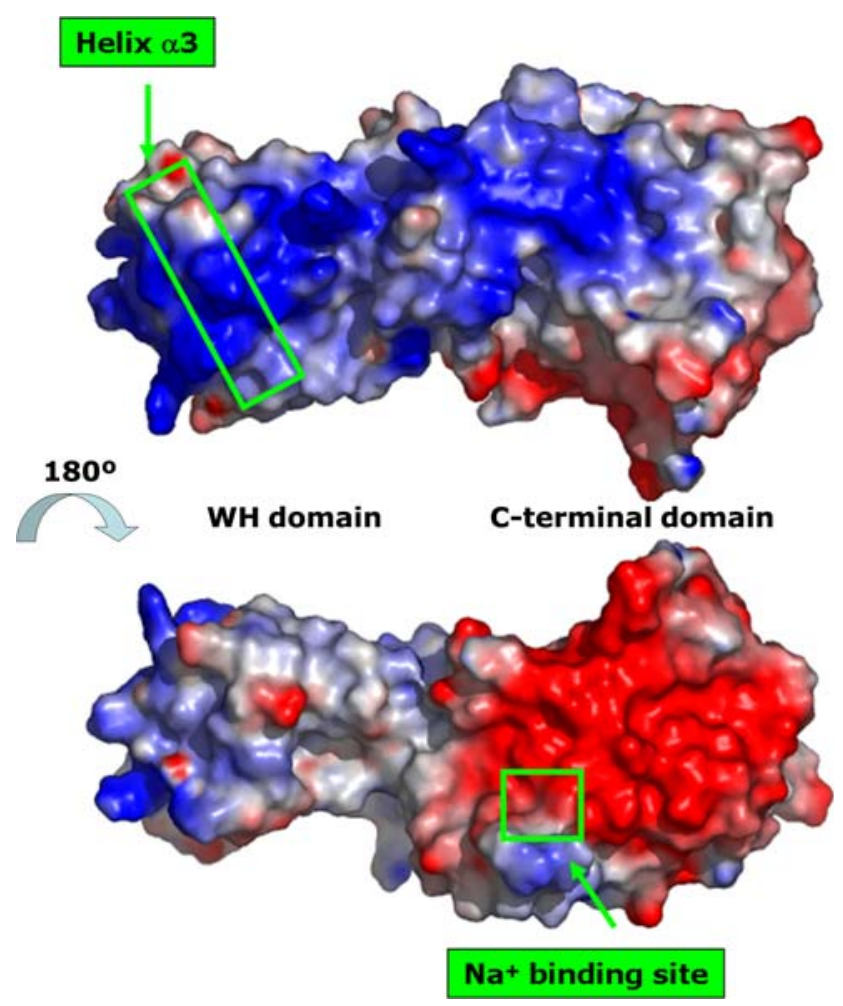

Fig. 4 Surface presentation of M. tuberculosis Rv2827c, showing the electrostatic potential. The figure was prepared using PYMOL (www.pymol.org). The distribution of the electrostatic surface potential indicates that one side of the protein is negatively charged (red); this area includes the metal binding site. On the opposite side there is a continuous positively charged patch extending for the entire length of the molecule (blue), which includes the potential nucleic acid binding motif in the N-terminal domain containing the $\alpha 3$ helix

structure of the putative minimal nucleotidyltransferase (NMR structure, PDB code 1WOT, Suzuki et al. unpubl. data). For the fragment Ser212-Arg251, which is the parallel three-helix bundle $(\alpha 12, \alpha 13$, and $\alpha 14)$ several other structures were identified. Among them are the hypothetical protein ST1625p from the hyperthermophilic archaeon Sulfolobus tokodaii (PDB code 1WY6, [83]) and human PEX5 (PDB code 1FCH, [30]). For the fragment Leu175Ala295, no other similar structure could be identified, indicating that this fragment is unique, despite a sequence identity of $29 \%$ to 6-hydroxymethyl-7,8-dihydropterin pyrophosphokinase from E. coli (PDB code 1RU1, [8]).

The sodium binding site

The C-terminal domain of Rv2827c subunit harbors a metal binding site formed by two Asp residues, one water molecule and the side chain of an Arg residue. In the refined structure the metal ion has been identified as $\mathrm{Na}^{+}$, although both $\mathrm{Na}^{+}$and $\mathrm{K}^{+}$were present in the crystallization solution at concentrations of $1.0 \mathrm{M}$ and $0.075 \mathrm{M}$, respectively. The coordination number for the metal ion is six with the Me...X distances in chains $\mathrm{A}$ and $\mathrm{B}$ being 2.25 and $2.28 \AA$ (Asp206-OD1), 2.55 and $2.44 \AA$ (Asp206-O), 2.26 and $2.38 \AA$ (Asp210-OD1), 2.46 and $2.54 \AA$ (Asp210OD2), 2.43, $2.27 \AA$ (water-O) and 3.10 and $3.28 \AA$ (Arg164-CZ). If the two carboxylate oxygens of Asp210 are counted as two ligands, the coordination geometry of the metal ion constitutes a distorted octahedron. This, together with the observed distances favors the presence of $\mathrm{Na}^{+}$over $\mathrm{K}^{+}$[35]. An analysis of the bond-valence parameters [12-14, 53] confirms this observation. The values of this parameter for $\mathrm{Na}^{+}$are 1.16 and 1.31 (for the site in chains A and B, respectively), which is close to the expected value for this ion, while for $\mathrm{K}^{+}$the values are 2.82 and 2.99. An usual feature of this site is that the guanidinium side chain of Arg164 is placed such that is

Fig. 5 Stereo view of the metal binding site in the C-terminal domain of Rv2827c. The unusual coordination of the metal ion by an Arg residue via a $\pi$-interaction is shown in green. The distances between the metal ion and the ligands are given in $\AA$
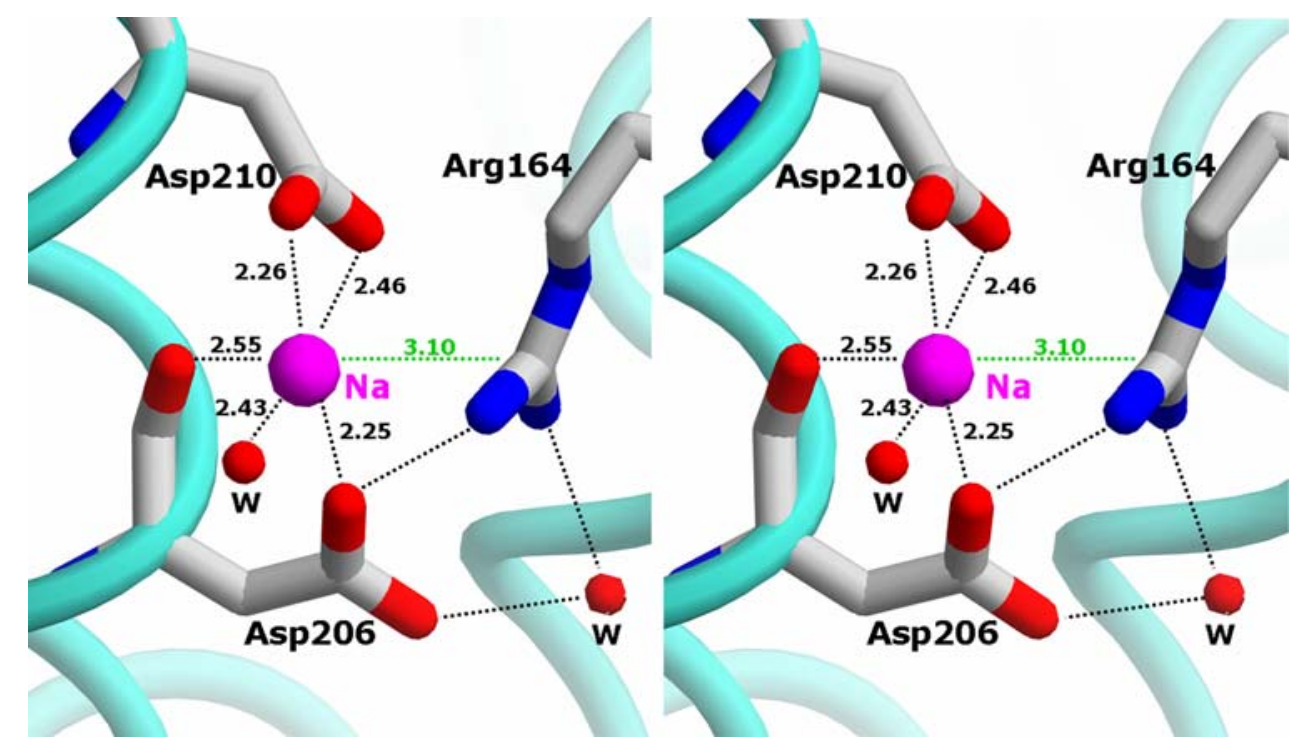
makes a $\pi$-contact with the metal ion while its hydrogen atoms are involved in interactions with Leu110-O, Asp206$\mathrm{O}$ and a water molecule (Fig. 5). In the crystal structure of the $\mathrm{GABA}(\mathrm{A})$ repressor-associated protein (PDB code 1KJT, [5]) $\mathrm{Na}^{+}$is also coordinated by an Arg side chain but in this case, the NH1-atom of Arg65 is directed toward the $\mathrm{Na}^{+}$so that a $\pi$-contact as the one found in Rv2827c can not form. The role of the metal binding site in Rv2827c is unknown. It is located on the opposite side of the protein with respect to the potential nucleic acid binding site, in the region with mostly negatively charged character. It may thus just serve the purpose of structurally stabilizing the protein.

\section{DNA binding properties of Rv2827c}

Initial hints toward DNA binding properties of Rv2827c were obtained from experiments, which revealed that in the presence of DNA Rv2827c becomes more stable in solution and remains soluble even at low imidazole concentrations. Without DNA, Rv2827c is only stable at high concentrations of imidazole [38]. Of the four randomly chosen DNA sequences tried (Table 3), three were able to stabilize Rv2827c. Only the 26-bp fragment taken from the DNA complex of interferon regulatory factor 1 (PDB code 1IF1, [25]) did not stabilize Rv2827c, which precipitated during the dialysis. Neither the sequences nor the $\mathrm{G}+\mathrm{C}$ content of the nucleotides used in the experiment provide an explanation for this phenomenon. A DNA binding test using the PCR-assisted binding site selection method [56] clearly demonstrated that Rv2827c possesses dsDNA binding capability. However, the DNA sequences derived from the 17 randomly picked clones did not reveal any sequence preference (Table 4). Based on this experiment we can only conclude that Rv2827c binds DNA in a nonspecific manner.

Model of the complex of Rv2827c with DNA

A superposition of the N-terminal domain of Rv2827c and the WH domain of the interferon regulatory factor 3 (IRF3, PDB code 1T2 K, [64]) complexed with a 31-mer DNA fragment results in the model shown in Fig. 6a. The DNA fragment fits well to the positively charged N-terminal domain, and it continues alongside Rv2827c next to the positively charged side of the C-terminal domain (Fig. 4). If the C-terminal domain is slightly rotated relative to the $\mathrm{N}$-terminal domain by adjusting the orientation of the $\mathrm{C}$ terminal domain, then fit can be markedly improved (Fig. 6b). An ASA calculation on the Rv2827c/DNAcomplex model reveals that DNA binding buries $1,330 \AA^{2}$ of surface area of Rv2827c, which amounts to $8.7 \%$ of its

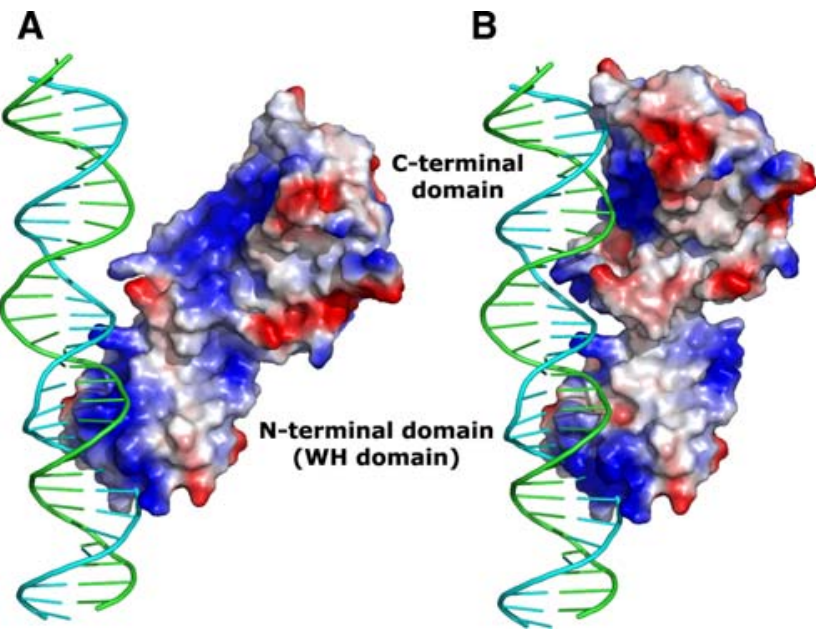

Fig. 6 Interaction of Rv2827c with B-DNA. In a the structure of Rv2827c as determined is shown, whereas in b the model of Rv2827c which was obtained after adjusting the orientation of the C-terminal domain

total surface. This lends further support to the hypothesis that Rv2827c is a DNA binding protein. In an anomalous difference Fourier map calculated based on the $\mathrm{Br}$ peak data set, 23 bromide binding sites can be identified. All but one bromide binding sites are conserved and occur in both independent molecules in the asymmetric unit. Four out of eleven sites in chain $\mathrm{A}$ and four out of twelve sites in chain $\mathrm{B}$ are located in the protein-DNA interface. This indicates a clear preference for negatively charged bromide ions to bind to the potential positively charged DNA binding surface further supporting the DNA binding hypothesis and the model of the Rv2827c/DNA complex.

\section{Conclusions}

In this article we present the three-dimensional structure of the hypothetical protein Rv2827c from Mtb determined at $1.93 \AA$ resolution using the three-wavelength anomalous diffraction method. Rv2827c consists of two structural domains. The structure of the C-terminal domain of Rv2827c constitutes a novel fold whereas the structure of the N-terminal domain of Rv2827c exhibits a winged helix topology. A structural $\mathrm{Na}^{+}$binding site was identified with an unusual coordination of the metal ion by a guanidinium side chain of Arg. It could also be shown that the presence of oligonucleotides can stabilize Rv2827c and prevent spontaneous precipitation in imidazole-free buffer. Furthermore, by PCR-assisted binding site selection it was demonstrated that Rv2827c indeed binds dsDNA. The analysis of the charge of the accessible surface area of Rv2827c suggests that both domains are involved in the interaction with DNA or RNA. 
Acknowledgements We would like to thank Dr. L. Jeanne Perry (UCLA) for providing genomic Mtb H37Rv DNA and the X-Mtb consortium (www.xmtb.org) for funding through BMBF/PTJ grant no. BIO/0312992A.

\section{References}

1. Alexandrov NN, Nussinov R, Zimmer RM (1995). Fast protein fold recognition via sequence to structure alignment and contact capacity potentials. In: Hunter L, Klein TE (eds) Pacific symposium on biocomputing '96. World Scientific Publishing Co., Singapore, pp 53-72

2. Altschul SF, Madden TL, Schaffer AA, Zhang J, Zhang Z, Miller W, Lipman DJ (1997) Gapped BLAST and PSI-BLAST: a new generation of protein database search programs. Nucleic Acids Res 25:3389-3402. doi:10.1093/nar/25.17.3389

3. Arunkumar AI, Klimovich V, Jiang X, Ott RD, Mizoue L, Fanning E, Chazin WJ (2005) Insights into hRPA32 C-terminal domain-mediated assembly of the simian virus 40 replisome. Nat Struct Mol Biol 12:332-339. doi:10.1038/nsmb916

4. Bateman A, Birney E, Durbin R, Eddy SR, Howe KL, Sonnhammer EL (2000) The Pfam protein families database. Nucleic Acids Res 28:263-266. doi:10.1093/nar/28.1.263

5. Bavro VN, Sola M, Bracher A, Kneussel M, Betz H, Weissenhorn W (2002) Crystal structure of the GABA(A)-receptor-associated protein, GABARAP. EMBO Rep 3:183-189. doi:10.1093/emboreports/kvf026

6. Bentley SD, Chater KF, Cerdeno-Tarraga AM, Challis GL, Thomson NR, James KD, Harris DE, Quail MA, Kieser H, Harper D, Bateman A, Brown S, Chandra G, Chen CW, Collins M, Cronin A, Fraser A, Goble A, Hidalgo J, Hornsby T, Howarth S, Huang CH, Kieser T, Larke L, Murphy L, Oliver K, O'Neil S, Rabbinowitsch E, Rajandream MA, Rutherford K, Rutter S, Seeger K, Saunders D, Sharp S, Squares R, Squares S, Taylor K, Warren T, Wietzorrek A, Woodward J, Barrell BG, Parkhill J, Hopwood DA (2002) Complete genome sequence of the model actinomycete Streptomyces coelicolor A3(2). Nature 417:141147. doi:10.1038/417141a

7. Berman HM, Westbrook J, Feng Z, Gilliland G, Bhat TN, Weissig H, Shindyalov IN, Bourne PE (2000) The protein data bank. Nucleic Acids Res 28:235-242. doi:10.1093/nar/28.1.235

8. Blaszczyk J, Li Y, Wu Y, Shi G, Ji X, Yan H (2004) Essential roles of a dynamic loop in the catalysis of 6-hydroxymethyl-7,8dihydropterin pyrophosphokinase. Biochemistry 43:1469-1477. doi:10.1021/bi0360531

9. Brennan RG (1993) The winged-helix DNA-binding motif: another helix-turn-helix takeoff. Cell 74:773-776. doi:10.1016/ 0092-8674(93)90456-Z

10. Brennan RG, Matthews BW (1989) The helix-turn-helix DNA binding motif. J Biol Chem 264:1903-1906

11. Brennan RG, Takeda Y, Kim J, Anderson WF, Matthews BW (1986) Crystallization of a complex of cro repressor with a 17 base-pair operator. J Mol Biol 188:115-118. doi:10.1016/00222836(86)90488-2

12. Brese NE, O'Keeffe M (1991) Bond-valence parameters for solids. Acta Crystallogr B 47:192-197. doi:10.1107/S0108768 190011041

13. Brown ID (1977) Predicting bond lengths in inorganic crystals. Acta Crystallogr B 33:1305-1310. doi:10.1107/S0567740877 005998

14. Brown ID, Altermatt D (1985) Bond-valence parameters obtained from a systematic analysis of the inorganic crystal structure database. Acta Crystallogr B 41:244-247. doi:10.1107/S01087 68185002063
15. Camus J-C, Pryor MJ, Médigue C, Cole ST (2002) Re-annotation of the genome sequence of Mycobacterium tuberculosis H37Rv. Microbiology 148:2967-2973

16. Carreno-Lopez R, Sanchez-Villa A, Camargo-Diaz N, Elmerich C, Baca BE (2006) Characterization of chsA, a new gene controlling the chemotactic response, in Azospirillum brasilense Sp7. EMBL/GenBank/DDBJ

17. CCP4, Collaborative Computational Project, Number 4 (1994) Acta Crystallogr. D50:760-763

18. Chatake T, Mizuno N, Voordouw G, Higuchi Y, Arai S, Tanaka I, Niimura N (2003) Crystallization and preliminary neutron analysis of the dissimilatory sulfite reductase $\mathrm{D}(\mathrm{DsrD})$ protein from the sulfate-reducing bacterium Desulfovibrio vulgaris. Acta Crystallogr D Biol Crystallogr 59:2306-2309. doi:10.1107/S090 7444903020596

19. Clark KL, Halay ED, Lai E, Burley SK (1993) Co-crystal structure of the HNF-3/fork head DNA recognition motif resembles histone H5. Nature 364:412-420. doi:10.1038/3644 $12 \mathrm{a} 0$

20. Cohen GE (1997) ALIGN: a program to superimpose protein coordinates, accounting for insertions and deletions. J Appl Cryst 30:1160-1161. doi:10.1107/S0021889897006729

21. Cole ST, Brosch R, Parkhill J, Garnier T, Churcher C, Harris D et al (1998) Deciphering the biology of Mycobacterium tuberculosis from the complete genome sequence. Nature 393:537544. doi:10.1038/31159

22. Cowtan K (1994) Joint CCP4 and ESF-EACBM newsletter on protein crystallography 31:34-38

23. Dauter Z, Dauter M, Rajashankar KR (2000) Novel approach to phasing proteins: derivatization by short cryo-soaking with halides. Acta Crystallogr D Biol Crystallogr 56:232-237. doi: 10.1107/S0907444999016352

24. Emsley P, Cowtan K (2004) Coot: model-building tools for molecular graphics. Acta Crystallogr D Biol Crystallogr 60: 2126-2132. doi:10.1107/S0907444904019158

25. Escalante CR, Yie J, Thanos D, Aggarwal AK (1998) Structure of IRF-1 with bound DNA reveals determinants of interferon regulation. Nature 391:103-106. doi:10.1038/34224

26. French GS, Wilson KS (1978) On the treatment of negative intensity observations. Acta Crystallogr A 34:517-525. doi: $10.1107 / \mathrm{S} 0567739478001114$

27. Gajiwala KS, Burley SK (2000) Winged helix proteins. Curr Opin Struct Biol 10:110-116. doi:10.1016/S0959-440X(99)00 057-3

28. Gajiwala KS, Chen H, Cornille F, Roques BP, Reith W, Mach B, Burley SK (2000) Structure of the winged-helix protein hRFX1 reveals a new mode of DNA binding. Nature 403:916-921. doi: $10.1038 / 35002634$

29. Garnier T, Eiglmeier K, Camus J-C, Medina N, Mansoor H, Pryor M, Duthoy S, Grondin S, Lacroix C, Monsempe C, Simon S, Harris B, Atkin R, Doggett J, Mayes R, Keating L, Wheeler PR, Parkhill J, Barrell BG, Cole ST, Gordon SV, Hewinson RG (2003) The complete genome sequence of Mycobacterium bovis. Proc Natl Acad Sci USA 100:7877-7882. doi:10.1073/pnas. 1130426100

30. Gatto GJ Jr, Geisbrecht BV, Gould SJ, Berg JM (2000) Peroxisomal targeting signal-1 recognition by the TPR domains of human PEX5. Nat Struct Biol 7:1091-1095. doi:10.1038/81930

31. Gibrat JF, Madej T, Bryant SH (1996) Surprising similarities in structure comparison. Curr Opin Struct Biol 6:377-385. doi: 10.1016/S0959-440X(96)80058-3

32. Ha SC, Lokanath NK, Van Quyen D, Wu CA, Lowenhaupt K, Rich A, Kim YG, Kim KK (2004) A poxvirus protein forms a complex with left-handed Z-DNA: crystal structure of a Yatapoxvirus Zalpha bound to DNA. Proc Natl Acad Sci USA 101:14367-14372. doi:10.1073/pnas.0405586101 
33. Haering CH, Schoffnegger D, Nishino T, Helmhart W, Nasmyth K, Lowe J (2004) Structure and stability of cohesin's Smc1kleisin interaction. Mol Cell 15:951-964. doi:10.1016/j.molcel. 2004.08.030

34. Hao Q (2004) ABS: a program to determine absolute configuration and evaluate anomalous scatterer substructure. J Appl Cryst 37:498-499. doi:10.1107/S0021889804008696

35. Harding MM (2002) Metal-ligand geometry relevant to proteins and in proteins: sodium and potassium. Acta Crystallogr D Biol Crystallogr 58:872-874. doi:10.1107/S0907444902003712

36. Hendrickson WA (1985) Analysis of protein structure from diffraction measurement at multiple wavelengths. Trans Am Crystallogr Assoc 21:11-21

37. Huffman JL, Brennan RG (2002) Prokaryotic transcription regulators: more than just the helix-turn-helix motif. Curr Opin Struct Biol 12:98-106. doi:10.1016/S0959-440X(02)00295-6

38. Janowski R, Nasser Eddine A, Kaufmann SHE, Weiss MS (2006) Cloning, expression, purification, crystallization and preliminary X-ray diffraction analysis of Rv2827c from Mycobacterium tuberculosis. Acta Crystallogr F62:753-756

39. Kahmann JD, Wecking DA, Putter V, Lowenhaupt K, Kim Y-G, Schmieder P, Oschkinat H, Rich A, Schade M (2004) The solution structure of the N-terminal domain of E3L shows a tyrosine conformation that may explain its reduced affinity to Z-DNA in vitro. Proc Natl Acad Sci USA 101:2712-2717. doi:10.1073/ pnas.0308612100

40. Kaufmann SHE, Parida SK (2008) Tuberculosis in Africa: learning from pathogenesis for biomarker identification. Cell Host Microbe 4:219-228. doi:10.1016/j.chom.2008.08.002

41. Kodandapani R, Pio F, Ni CZ, Piccialli G, Klemsz M, McKercher S, Maki RA, Ely KR (1996) A new pattern for helix-turn-helix recognition revealed by the PU1 ETS-domain-DNA complex. Nature 380:456-460. doi:10.1038/380456a0

42. Krissinel E, Henrick K (2004) Secondary-structure matching (SSM), a new tool for fast protein structure alignment in three dimensions. Acta Crystallogr D Biol Crystallogr 60:2256-2268. doi:10.1107/S0907444904026460

43. Krissinel E, Henrick K (2005) Detection of protein assemblies in crystals. In: Berthold MR et al (eds) CompLife 2005. SpringerVerlag, Berlin, pp 163-174 LNBI 3695

44. Lamichhane G, Zignol M, Blades NJ, Geiman DE, Dougherty A, Grosset J, Broman KW, Bishai WR (2003) A postgenomic method for predicting essential genes at subsaturation levels of mutagenesis: application to Mycobacterium tuberculosis. Proc Natl Acad Sci USA 100:7213-7218. doi:10.1073/pnas.123143 2100

45. Laskowski RA, MacArthur MW, Moss DS, Thornton JM (1993) PROCHECK: a program to check the stereochemical quality of protein structures. J Appl Cryst 26:283-291. doi:10.1107/S002 1889892009944

46. Littlefield O, Nelson HC (1999) A new use for the 'wing' of the 'winged' helix-turn-helix motif in the HSF-DNA cocrystal. Nat Struct Biol 6:464-470. doi:10.1038/8269

47. Liu H, Zhang JJ, Wang SJ, Zhang XE, Zhou NY (2005) Plasmidborne catabolism of methyl parathion and p-nitrophenol in Pseudomonas sp strain WBC-3. Biochem Biophys Res Commun 334:1107-1114. doi:10.1016/j.bbrc.2005.07.006

48. Madej T, Gibrat JF, Bryant SH (1995) Threading a database of protein cores. Proteins 23:356-369. doi:10.1002/prot.340230309

49. Magis C, Gasparini D, Lecoq A, Le Du MH, Stura E, Charbonnier JB, Mourier G, Boulain JC, Pardo L, Caruana A, Joly A, Lefranc M, Masella M, Menez A, Cuniasse P (2006) Structurebased secondary structure-independent approach to design protein ligands: application to the design of Kv12 potassium channel blockers. J Am Chem Soc 128:16190-16205. doi:10.1021/ja06 46491
50. Melckebeke HV, Vreuls C, Gans P, Llabres G, Joris B, Simorre JP (2003) Solution structural study of BlaI: implications for the repression of genes involved in beta-lactam antibiotic resistance. J Mol Biol 333:711-720. doi:10.1016/j.jmb.2003.09.005

51. Mo Y, Ho W, Johnston K, Marmorstein R (2001) Crystal structure of a ternary SAP-1/SRF/c-fos SRE DNA complex. J Mol Biol 314:495-506. doi:10.1006/jmbi.2001.5138

52. Morris RJ, Zwart PH, Cohen S, Fernandez FJ, Kakaris M, Kirillova O, Vonrhein C, Perrakis A, Lamzin VS (2004) Breaking good resolutions with ARP/wARP. J Synchr Rad 11:56-59. doi: 10.1107/S090904950302394X

53. Müller P, Köpke S, Sheldrick GM (2003) Is the bond-valence method able to identify metal atoms in protein structures? Acta Crystallogr D Biol Crystallogr 59:32-37. doi:10.1107/S0907444 902018000

54. Murshudov GN, Vagin A, Dodson E (1997) Refinement of macromolecular structures by the maximum-likelihood method. Acta Crystallogr D Biol Crystallogr 53:240-255. doi:10.1107/ S0907444996012255

55. Nicholls A, Sharp KA, Honig B (1991) GRASP-graphical representation and analysis of structural properties. Proteins 11:281-296. doi:10.1002/prot.340110407

56. Nørby PL, Pallisgaard N, Pedersen FS, Jørgensen P (1992) Determination of recognition-sequences for DNA-binding proteins by a polymerase chain reaction assisted binding site selection method (BSS) using nitrocellulose immobilized DNA binding protein. Nucleic Acids Res 20:6317-6321. doi:10.1093/ nar/20.23.6317

57. Omura S, Ikeda H, Ishikawa J, Hanamoto A, Takahashi C, Shinose M, Takahashi Y, Horikawa $\mathrm{H}$, Nakazawa $\mathrm{H}$, Osonoe T, Kikuchi H, Shiba T, Sakaki Y, Hattori M (2001) Genome sequence of an industrial microorganism Streptomyces avermitilis: deducing the ability of producing secondary metabolites. Proc Natl Acad Sci USA 98:12215-12220. doi:10.1073/pnas. 211433198

58. Orengo CA, Michie AD, Jones S, Jones DT, Swindells MB, Thornton JM (1997) CATH-A hierarchic classification of protein domain structures. Structure 5:1093-1108. doi:10.1016/ S0969-2126(97)00260-8

59. Otwinowski Z, Minor W (1997) Processing of X-ray diffraction data collected in oscillation mode. Methods Enzymol 276:307326. doi:10.1016/S0076-6879(97)76066-X

60. Painter J, Merritt EA (2006) Optimal description of a protein structure in terms of multiple groups undergoing TLS motion. Acta Crystallogr D Biol Crystallogr 62:439-450. doi:10.1107/ S0907444906005270

61. Painter J, Merritt EA (2006) TLSMD web server for the generation of multi-group TLS models. J Appl Cryst 39:109-111. doi: $10.1107 /$ S0021889805038987

62. Pal D, Eisenberg D (2005) Inference of protein function from protein structure. Structure 13:121-130. doi:10.1016/j.str.2004. 10.015

63. Panjikar S, Parthasarathy V, Lamzin VS, Weiss MS, Tucker PA (2005) Auto-Rickshaw: an automated crystal structure determination platform as an efficient tool for the validation of an X-ray diffraction experiment. Acta Crystallogr D Biol Crystallogr 61:449-457. doi:10.1107/S0907444905001307

64. Panne D, Maniatis T, Harrison SC (2004) Crystal structure of ATF-2/c-Jun and IRF-3 bound to the interferon-beta enhancer. EMBO J 23:4384-4393. doi:10.1038/sj.emboj.7600453

65. Perrakis A, Morris RJ, Lamzin VS (1999) Automated protein model building combined with iterative structure refinement. Nat Struct Biol 6:458-463. doi:10.1038/8263

66. Rachman H, Strong M, Schaible U, Schuchhardt J, Hagens K, Mollenkopf H, Eisenberg D, Kaufmann SHE (2006) Mycobacterium tuberculosis gene expression profiling within the context 
of protein networks. Microbes Infect 8:747-757. doi:10.1016/ j.micinf.2005.09.011

67. Rachman H, Strong M, Ulrichs T, Grode L, Schuchhardt J, Mollenkopf H, Kosmiadi GA, Eisenberg D, Kaufmann SHE (2006) Unique transcriptome signature of Mycobacterium tuberculosis in pulmonary tuberculosis. Infect Immun 74:1233-1242. doi:10.1128/IAI.74.2.1233-1242.2006

68. Ramakrishnan V, Finch JT, Graziano V, Lee PL, Sweet RM (1993) Crystal structure of globular domain of histone H5 and its implications for nucleosome binding. Nature 362:219-223. doi: $10.1038 / 362219 \mathrm{a} 0$

69. Sam MD, Cascio D, Johnson RC, Clubb RT (2004) Crystal structure of the excisionase-DNA complex from bacteriophage lambda. J Mol Biol 338:229-240. doi:10.1016/j.jmb.2004.02.053

70. Sassetti CM, Boyd DH, Rubin EJ (2003) Genes required for mycobacterial growth defined by high density mutagenesis. Mol Microbiol 48:77-84. doi:10.1046/j.1365-2958.2003.03425.x

71. Schneider TR, Sheldrick GM (2002) Substructure solution with SHELXD. Acta Crystallogr D Biol Crystallogr 58:1772-1779. doi:10.1107/S0907444902011678

72. Schwartz T, Rould MA, Lowenhaupt K, Herbert A, Rich A (1999) Crystal structure of the Zalpha domain of the human editing enzyme ADAR1 bound to left-handed Z-DNA. Science 284:1841-1845. doi:10.1126/science.284.5421.1841

73. Sheldrick GM (2002) Macromolecular phasing with SHELXE. Z Kristallogr 217:644-650. doi:10.1524/zkri.217.12.644.20662

74. Sheldrick GM, Hauptman HA, Weeks CM, Miller R, Usón I (2001) In: Rossmann MG, Arnold E (eds) International tables for macromolecular crystallography, vol F. Kluwer Academic Publishers, Dordrecht, pp 333-345 Chapter 16

75. Slesarev AI, Mezhevaya KV, Makarova KS, Polushin NN, Shcherbinina OV, Shakhova VV, Belova GI, Aravind L, Natale DA, Rogozin IB, Tatusov RL, Wolf YI, Stetter KO, Malykh AG, Koonin EV, Kozyavkin SA (2002) The complete genome of hyperthermophile Methanopyrus kandleri AV19 and monophyly of archaeal methanogens. Proc Natl Acad Sci USA 99:46444649. doi:10.1073/pnas.032671499

76. Suhre K, Sanejouand YH (2004) ElNemo: a normal mode webserver for protein movement analysis and the generation of templates for molecular replacement. Nucleic Acids Res 32:W610-W614. doi:10.1093/nar/gkh368

77. Tatusov RL, Natale DA, Garkavtsev IV, Tatusova TA, Shankavaram UT, Rao BS, Kiryutin B, Galperin MY, Fedorova ND, Koonin EV (2001) The COG database: new developments in phylogenetic classification of proteins from complete genomes. Nucleic Acids Res 29:22-28. doi:10.1093/nar/29.1.22

78. Vaguine AA, Richelle J, Wodak SJ (1999) SFCHECK: a unified set of procedures for evaluating the quality of macromolecular structure-factor data and their agreement with the atomic model. Acta Crystallogr D Biol Crystallogr 55:191-205. doi:10.1107/ S0907444998006684

79. Weiss MS (2001) Global indicators of X-ray data quality. J Appl Cryst 34:130-135. doi:10.1107/S0021889800018227

80. WHO (2008) Global tuberculosis control: surveillance, planning, financing WHO, Geneva http://www.who.int/tb/publications/ global_report/en/index.html

81. Wilson KP, Shewchuk LM, Brennan RG, Otsuka AJ, Matthews BW (1992) Escherichia coli biotin holoenzyme synthetase/bio repressor crystal structure delineates the biotin- and DNA-binding domains. Proc Natl Acad Sci USA 89:9257-9261. doi: 10.1073/pnas.89.19.9257

82. Winn MD, Isupov MN, Murshudov GN (2001) Use of TLS parameters to model anisotropic displacements in macromolecular refinement. Acta Crystallogr D Biol Crystallogr 57:122-133. doi:10.1107/S0907444900014736

83. Yoneda K, Sakuraba H, Tsuge H, Katunuma N, Kuramitsu S, Kawabata T, Ohshima T (2005) The first crystal structure of an archaeal helical repeat protein. Acta Crystallogr F61:636-639

84. Young D, Stark J, Kirschner D (2008) Systems biology of persistent infection: tuberculosis as a case study. Nat Rev Microbiol 6:520-528. doi:10.1038/nrmicro1919

85. Zheng N, Fraenkel E, Pabo CO, Pavletich NP (1999) Structural basis of DNA recognition by the heterodimeric cell cycle transcription factor E2F-DP. Genes Dev 13:666-674. doi:10.1101/ gad.13.6.666 